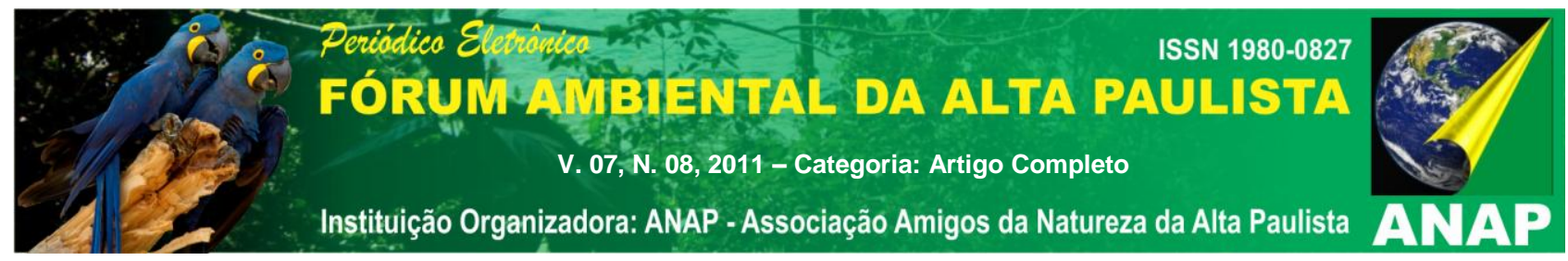

\title{
AQUECENDO A TERRA EM SETE LINHAS: A GRITANTE REORIENTAÇÃO DA SOCIEDADE IMPOSTA POR RESULTADOS DE MODELAGEM EM COMPUTADORES
}

\author{
Ricardo Augusto Felicio ${ }^{1}$
}

\section{Daniela de Souza Onça ${ }^{2}$}

RESUMO: O mundo em que vivemos está cada vez mais controlado por computadores, os quais são programados para executar essas funções ou apresentar resultados para todas as finalidades humanas. Para a ciência climática, um amplo uso dos computadores é aplicado em processar modelos matemáticos de clima que visam apresentar cenários dos supostos problemas gerados pelas "mudanças climáticas" e o "aquecimento global". Assim sendo, o trabalho apresentou uma crítica aos modelos usados nestas pesquisas climáticas em sua base epistemológica, avaliando alguns elementos da realidade e como são "interpretados" por estes modelos de computador. Pretendeu-se apresentar também um exemplo bem simples de algoritmo matemático, através de um código de programa extremamente manipulável, mas que conseguiu demonstrar como os modelos são programados para responderem exatamente os resultados que se esperam deles, neste caso, em que a elevação do $\mathrm{CO}_{2}$, sempre de origem antropogênica, determina tudo no planeta. Espera-se que a pesquisa torne mais claro para as pessoas em geral que tenham acesso às informações, de que todo o cotidiano de suas vidas tem sido reorientado, baseando-se em resultados de modelos matemáticos processados em computador, através de seus hipotéticos cenários, os quais estão muito longe de expressarem a realidade.

Palavras-chave: Mudanças Climáticas. Aquecimento Global. Modelagem.

\section{INTRODUÇÃO}

\footnotetext{
${ }_{1}^{1}$ Prof. Dr. Climatologista, Departamento de Geografia - USP. ricaftnt@yahoo.com.

${ }^{2}$ Prof $^{a}$. Dra . Climatologista, Departamento de Geografia - UDESC. danielaonca@yahoo.com.br.
} 


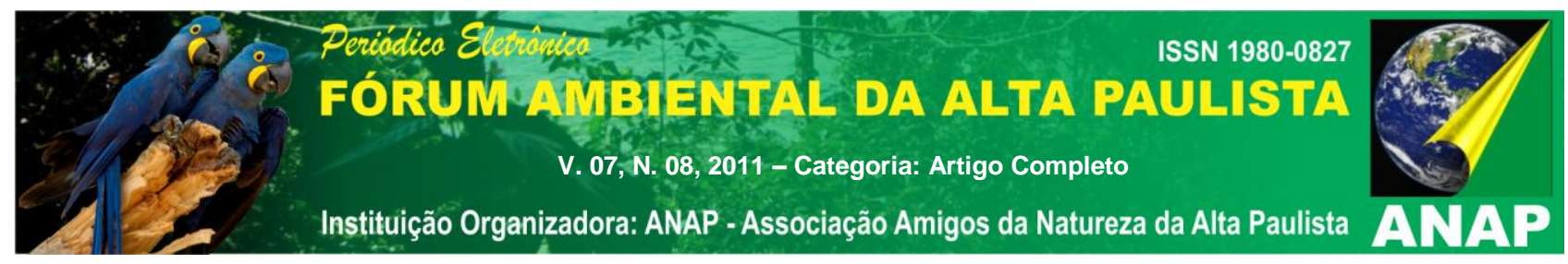

A todo momento que acessamos um canal da internet, ou vemos notícias por meio de jornais ou televisão, somos bombardeados pelo alarmismo cada vez mais crescente dos supostos problemas gerados pelas "mudanças climáticas" e pelo "aquecimento global". Poucos observam que todo este extremismo tem como base pesquisas pseudocientíficas que são moldadas em computadores, os quais geram saídas de cenários realizadas por modelos matemáticos. Estes modelos visam expressar relações ou correlações que, na maior parte das vezes, sequer existem ou não se sustentam, sempre baseadas em um único elemento. Neste caso, é a elevação do $\mathrm{CO}_{2} \mathrm{O}$ elemento que determina tudo nestas "pesquisas".

O mundo é cada vez mais controlado por computadores, os quais são programados para executar suas funções de controles ou apresentar resultados para todas as atividades ou finalidades humanas. É certo que não haja nenhuma destas que não possa fazer uso da tecnologia da informação. Contudo, computadores são feitos para executarem instruções que foram programados para fazer. Auxiliam nas atividades repetitivas e deveriam ser sempre utilizados para o benefício da vida humana. Contudo, como todos os progressos técnicos, observamos que os mesmos tem sido utilizados muito mais para controlar a vida cotidiana das pessoas do que de fato ajudá-las. Podemos ver isto em todos os processos governamentais, como exemplos, a Receita Federal, Administrações Públicas Governamentais para diversas taxações, DETRAN, entre outros. Mas quando se faz necessário que a agilidade dos mesmos seja utilizada para o bem dos serviços públicos, como rápida contagem de tempo do serviço social INSS ou outros afins, a coisa muda de figura.

Nesta realidade, também estão inseridos os modelos matemáticos que tentam expressar visões de mundo e seus processos. Dentro deste conjunto há uma rede baseada na Física da Atmosfera que tenta simular o que se conhece sobre a Mecânica de Fluidos e Termodinâmica, envoltas aos movimentos atmosféricos. Dentre as mais diversas aplicações, uma delas foi a elaboração dos prognósticos de tempo. Os cientistas envolvidos no processo de tentar modelar o funcionamento da atmosfera da Terra em escala sinóptica tinham plena razão de dizer que tais simulações eram uma vaga aproximação da realidade, embora ajudassem do entendimento de como seriam as 


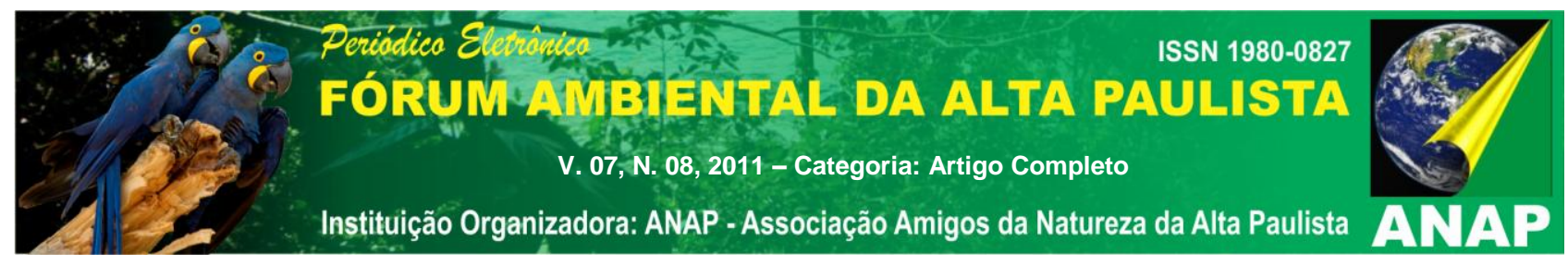

condições atmosféricas do tempo meteorológico em cerca de 12, 24 e 48h no futuro. Eles entendiam perfeitamente que tudo aquilo era uma simples representação de uma suposta realidade e nunca deveriam ser levados a sério sem um forte controle de qualidade, preferencialmente realizado por um profissional do tempo bem qualificado, portanto, um meteorologista de carreira operacional de fato. Contudo, uma gama de cientistas de outras áreas, principalmente de Física, Química, Eletrônica e Matemática, acharam interessante se aventurar por estas paragens e passaram a utilizar o suposto entendimento matemático da atmosfera da Terra, como um palco de acontecimentos para as mais mirabolantes simulações, sempre tentando basear-se nos movimentos da escala sinóptica, atrelando a termodinâmica às equações que deveriam reger o tempo meteorológico, pelo menos a princípio. Curiosamente, boa parte da estirpe de cientistas que trabalhavam com isto realizava simulações de como seria a atmosfera da Terra em caso de uma Guerra Termonuclear Global. O clímax destes cientistas ocorreu com a elaboração do filme "The Day After" (HUME, 1983), traduzido para o Brasil como "O Dia Seguinte". Neste filme de fiç̧ão que quase se aparentou como um documentário, são demonstrados os problemas referentes a uma guerra nuclear em escala global e toda a sorte de problemas que apareceriam, a posteriori, ao período de pós-guerra, onde os diversos cenários moldados pelos cientistas da época apresentavam um suposto inverno nuclear atingindo o planeta inteiro, dada a enorme quantidade de material lançado para a atmosfera, sem contar das partículas radioativas (BLÜCHEL, 2008).

Assim, com o fim da guerra fria já se anunciando, muitos anos antes da queda do muro de Berlim, uma parte destes cientistas começou a trabalhar em outros projetos de modelagem. Alguns foram para a NASA, modelar atmosferas de outros planetas. Contudo, uma boa parte destes permaneceu na mesma área, mas voltaram seus olhos para modelagens baseadas em dados que provavelmente foram tomados com uma certa perspectiva de objetivos mais obscuros. É o exemplo do ozônio sobre os pólos. Sempre se soube que os mesmos têm uma taxa de depleção muito alta nas saídas dos invernos, principalmente sobre a Antártida, que possui uma circulação atmosférica muito peculiar. Os dados já foram coletados desde os anos de 1930 e depois do Ano Geofísico Internacional, AGI de 1957 a 1959, em diversas localidades, sistematicamente (LINO, 2010). A conclusão já era sabida de muito tempo: sem Sol, sem ozônio! É simples assim, 


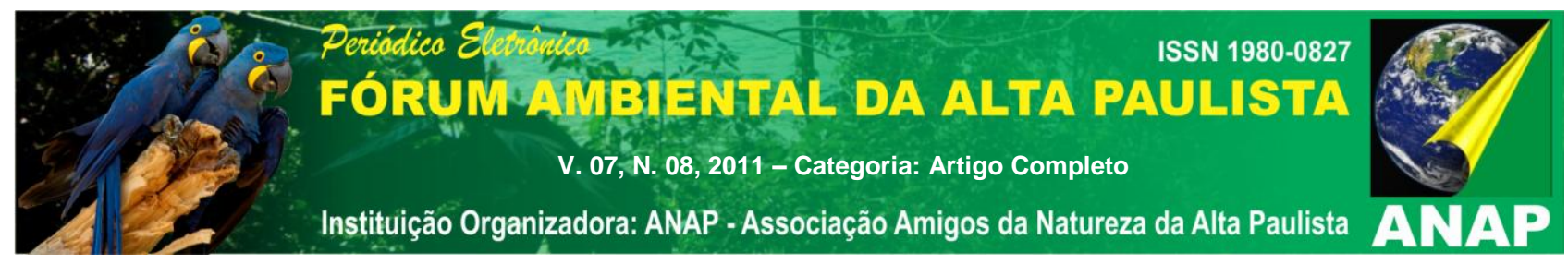

pois o mesmo necessita de radiação de ondas curtas na freqüência do ultravioleta $C$ incidindo sobre as moléculas do gás oxigênio para se formar. Sua depleção ocorre por qualquer coisa, incluindo outra molécula de ozônio e nada tem a ver com a presença de CFCs, que sequer existiam no começo do século XX. Criteriosamente esconderam o processo de formação e depleção do ozônio. O segundo maior constituinte da atmosfera, o oxigênio molecular $\left(\mathrm{O}_{2}\right)$ ao receber a radiação de alta energia da freqüência do Ultravioleta (UVC) parte-se em oxigênio atômico, cuja existência é altamente instável e necessita rapidamente de combinar com outras moléculas. No processo, há uma liberação de energia em forma de infravermelho termal. A seguir, as chances deste oxigênio atômico encontrar outro oxigênio atômico ou oxigênio molecular são muito elevadas. Quando este encontra o oxigênio molecular, formará a molécula de ozônio $\left(\mathrm{O}_{3}\right)$. Esta molécula em particular consegue interagir com a radiação de alta intensidade, porém em outro espectro, chamado de ultravioleta da faixa B (UVB). Assim sendo, notemos que para o processo ocorrer, faz-se necessário ter energia de radiação do espectro do ultravioleta, cuja fonte é o Sol. O fenômeno já era muito bem conhecido por Dobson que relatou em seu trabalho na Antártida, durante o próprio AGI (1957-1959) que "As anomalias do ozônio sobre a Antártida são naturais", justamente em uma época em que gases refrigerantes nem sequer existiam na escala industrial alcançada nos anos de 1980. Mesmo assim, a ciência da modelagem já começava a mostrar as suas garras, elaborando cenários de como seria uma atmosfera sem ozônio, isto quando não elencavam outros personagens ao conto do vigário, como toda a fauna e flora. Assim, criou-se em 1987 o IOTP, ou apenas o Painel do Ozônio.

A seguir, em 1988 surgia o IPCC, O Painel Intergovernamental de Mudanças Climáticas, que já se prontificava a utilizar todos os meios computacionais dos diversos centros de pesquisa que se oferecessem a serem colaboradores de seus relatórios. Assim sendo, uma boa parte dos cientistas modeladores atmosféricos que trabalhava para a guerra fria, arrumou uma nova forma de espalhar os seus medos: o "aquecimento global", que pintado por esses grandes artistas, ficaria tão tenebroso quanto a pior das catástrofes atômicas.

Nem mesmo com tantas e tantas evidências contrárias que os cientistas céticos apresentam para derrubar a ala dos aquecimentistas (pseudocientistas que trabalham 


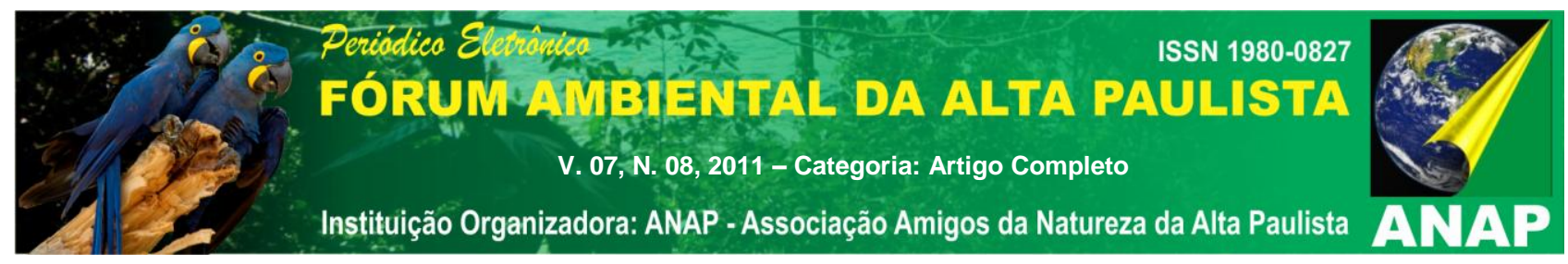

para a causa ideológica do aquecimento global antropogênico - AGA e suas sucursais infernais), continuamos a sofrer diariamente um bombardeio de falácias sobre este tema tão fantasioso. Mesmo a notícia de que cada vez mais vem crescendo a debandada dentro do IPCC, onde permanecem apenas os apoiadores da causa AGA. Em 2008, foram 650 cientistas que exigiram que seus nomes fossem removidos do painel. Até o presente momento, em 2011, a debandada atingiu mais de 1000, segundo o último relatório da Minoria do Senado Norte-americano (UNITED STATES SENATE, 2010). Curiosamente, todas as notícias que fazer referência às pesquisas realizadas para a causa AGA possuem uma receita de bolo já mapeada pelos céticos aqui do Brasil. Começam com um título apocalíptico para chamar a atenção do leitor. A seguir, fazem uma introdução do que seria o grande problema e, logo abaixo, no segundo parágrafo, quando no mais tardar está no terceiro, apresentam a EVIDÊNCIA dos resultados da pesquisa realizada: a saída de modelos matemáticos realizados em computador! Notem que a prova de que a pesquisa tem fundamento foi a modelagem feita e não uma prova concreta encontrada no empirismo ou em medições factuais e em quantidade suficiente para corroborar uma hipótese. Foram as linhas de código programadas em um computador que fizeram isto. E no final da notícia, vem o alarde retomando a mentira de sempre e que a pesquisa realizada aponta para os "cenários problemáticos para um futuro próximo".

\section{OBJETIVOS}

Demonstrar a precariedade dos modelos climáticos computacionais e sua falácia epistemológica em representar os elementos da realidade, bem como a visão de mundo. Em seguida, apresentar um algoritmo onde a forçante radiativa hipotética do dióxido de carbono é utilizada elegantemente para aquecer uma situação puntual, através de um modelo explícito em código de programação, finalizando como a única determinante da variação de temperatura. Assim, pretende-se demonstrar como essa saída simplificada, elevada a proporções mundiais, é utilizada para criar políticas públicas. 


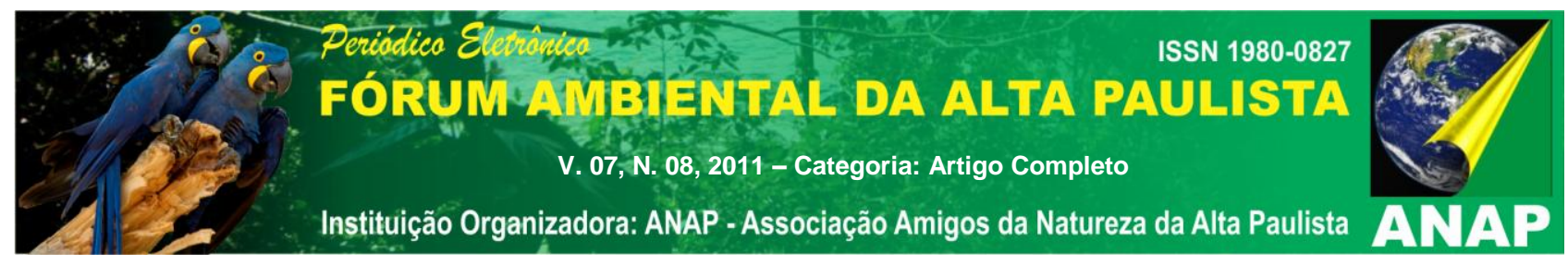

\section{MATERIAL E MÉTODOS}

A pesquisa foi dividida em duas partes. A primeira utilizou-se da metodologia de pesquisa direta às informações disponíveis, como publicações e sítios de internet, bem como diversas matérias jornalísticas de divulgação. Também se utilizou das experiências próprias dos autores ocorridas em debates contra pseudocientistas aquecimentistas, o que comprovou que as formas dos discursos, baseadas nas saídas de modelos de computador, permanecem muito vívidas. Na segunda parte, realizou-se o estudo de caso com a forçante radiativa hipoteticamente utilizada pelos aquecimentistas em seus modelos. Assim, escreveu-se um algoritmo para código de computador que simulasse uma saída puntual de projeção de temperatura para daqui a 100 anos. Expressaram-se dois cenários, tendo em vista que um deles era exorbitantemente forte, mostrando assim que os códigos são facilmente manipuláveis para apresentar os resultados que se desejam deles.

As inferências para as conclusões foram obtidas com as diversas reflexões e análises realizadas sobre todo o material avaliado. Pode-se notar, através do acompanhamento do raciocínio empregado, que os modelos são utilizados para nortear políticas públicas, mesmo muito longe de representarem a realidade.

\section{DISCUSSÃO DOS ELEMENTOS}

4.1 Os Computadores, a Tecnologia da Informação e os Modelos Matemáticos

Os computadores têm tomado vulto desde a década de 1940. A cada dez anos, seu nível de processamento, velocidade, memória interna e de massa tem se avolumado consideravelmente. Com a revolução da eletrônica moderna dos microchips digitais, os computadores passaram de analógicos (eletromecânicos contadores) para digitais (eletrônicos calculadores). O tempo foi passando e a ciência da computação foi evoluindo. Sua denominação variou de Processamento de Dados e Informática para Ciência da 


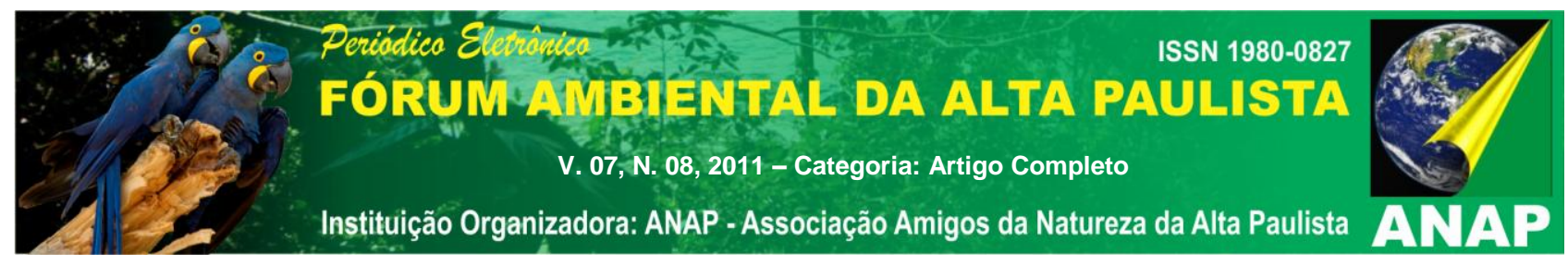

Computação. Atualmente, na presente geração, é denominada de Tecnologia da Informação. Contudo, todo esse aparato de hardware não é nada sem ter o elemento pensante por trás deles, ou seja, o software, ou códigos de programação. Assim sendo, os códigos são escritos com a finalidade de atenderem a um propósito. Seja realizar a folha de pagamento de uma empresa, ou administrar a trajetória de satélites em órbita, todos os códigos de programa, antes de serem escritos, precisam ser devidamente pensados, analisados e validados. Uma folha de pagamento possui fórmulas estabelecidas que calculam o tempo trabalhado, imposto devido, salário líquido etc. Um foguete lançado ao espaço recebe todo o controle realizado por computadores que foram programados para receber dados dos sensores e corrigirem plano de vôo, órbita e assim vai. Tais códigos de computador expressam fórmulas matemáticas. No caso da contabilidade, essas fórmulas são muito estáveis, imprimindo uma relação monotônica de fato. Para um processo mais complexo como a trajetória de um foguete, as equações se baseiam na mecânica clássica. Esta não está livre de cometer erros, mas estes são inerentes aos processos de medidas e podem ser levados em conta na formulação do código. Além disto, as equações que regem tais processos são também muito estáveis, principalmente quando querem expressar movimento, trajetórias etc.

Contudo, quando queremos utilizar a modelagem da dinâmica dos fluidos aplicada à atmosfera da Terra, a situação não se torna mais tão trivial ou estável. Deve-se ter a noção de que para realizar tal empreendimento, o analista necessitaria conhecer todos os processos que influenciariam na dinâmica a qual se propõe a modelar. Só por este fato, pode-se perceber que ele não conhece a totalidade dos elementos participantes, nem as relações entre eles, além de pouco estimar aquilo que poderia estar além do horizonte. Em um exemplo simples, onde os elementos são todos conhecidos e a relação entre eles também, tem-se:

$$
\mathrm{A}(\Delta \mathrm{t})=\mathrm{B}(\Delta \mathrm{t})+\mathrm{C}(\Delta \mathrm{t})+\mathrm{D}(\Delta \mathrm{t})
$$

o elemento A pode ser escrito através do conhecimento dos elementos B, C e D, aos quais a relação soma (+) foi estabelecida. Simultaneamente, a equação permite um movimento temporal que será útil para a realização dos processos de integração, tornando possível estabelecer o comportamento dos parâmetros dentro do tempo 


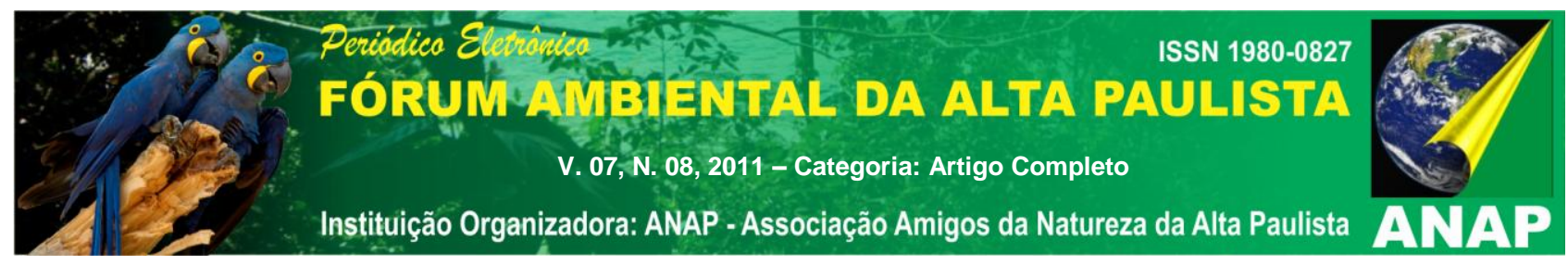

cronológico, tanto no futuro, quanto no passado. Um outro fator muito importante é que os elementos podem ser escritos em função dos outros, possibilitando o isolamento entre cada um. Contudo, a atmosfera da Terra não é simples como a Equação Diferencial que foi apresentada. Ela possui diversos processos internos e condições de contorno externas. Há também várias escalas de influência entre estes, sem contar que os principais fluxos de massa e energia possuem comportamentos muito pouco conhecidos. O Sol, os movimentos da mecânica celeste, a ação gravitacional, entre muitos outros são considerados os elementos extraterrestres de influência no clima. Já os oceanos, os vulcões, as nuvens e a Antártida são os principais elementos de influência interna (MOLION, 1994; MARUYAMA, 2009). Cada um deles envolve uma complexidade colossal em seus processos, dos quais, na prática, quase nada se sabe. Em suma, deve-se elencar então que não se conhece:

1 - A dinâmica da atmosfera, nem mesmo como um corpo isolado dos demais sistemas;

2 - A interação completa com os outros elementos do Estrato Geográfico;

3 - O comportamento integrado de seus constituintes e os níveis de ponderação.

Observando-se bem os três itens descritos acima, percebe-se que o entendimento do clima nunca será algo trivial, dado o número de fatores que estarão, a todo momento, fomentando suas influências, ora para mais, ora para menos, mas sempre surgindo um determinante aleatório que se sobrepujará aos demais, em todas as escalas, em um dado instante. Então, neste exato momento, torna-se crucial fazer a seguinte pergunta:

Se os computadores só trabalham com números, como expressar todos os processos da natureza climática em equações matemáticas?

A resposta, embora pareça estranha, é muito simples: NÃO CONSEGUEM! Não conseguem porque são os humanos que escrevem estas equações, através da sua interpretação ou visão de mundo, então necessitam saber de todas as leis que regem estas interações. Portanto, como não se conhece o sistema climático adequadamente, não se pode descrevê-lo adequadamente através destas equações matemáticas. Tudo 


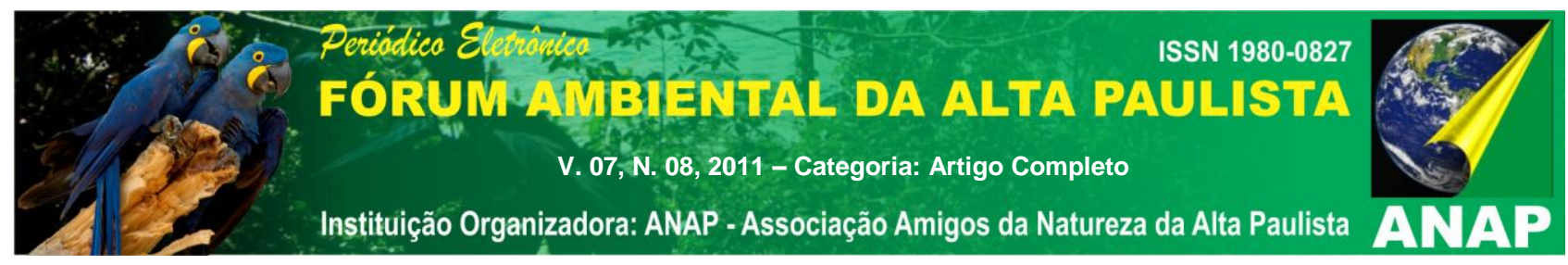

que se tem sobre modelos são suposições dos processos, muitos deles baseados em experimentos laboratoriais.

Os computadores estão longe de ter o poder de processar um modelo que atingisse um nível de complexidade que fosse suficientemente preciso em calcular todas as variáveis que pertencessem ao clima. Também temos os fatores de desconhecimento sobre quais são as variáveis envolvidas, desconhecimento dos processos, desconhecimento das interações, desconhecimento dos erros e intervenções escalares. Assim, os modelos são apenas uma abstração simplória, mas bonita de como eles acham que funcionaria o clima.

\subsection{Os Modelos Climáticos Utilizados pelo IPCC}

Ao se perguntar para o IPCC onde estão as provas de que é o dióxido de carbono emitido pelos humanos (e somente destes) o responsável pela suposta "mudança climática" ou "aquecimento global", recebe-se como resposta exatamente o que foi explanado acima: foram os modelos que nos deram esta evidência!

Assim, percebe-se que não há uma prova de fato e o IPCC vai apenas considerar como a grande evidência da influência dos humanos sobre o clima global, o fato de que os modelos climáticos empregados, quando rodados somente com forçamentos naturais, NÃO REPRODUZEM adequadamente os supostos padrões temporais e espaciais da evolução das temperaturas ao longo do século $X X$, que só podem ser adequadamente reproduzidos quando incluem forçamentos antropogênicos (IPCC, 2007, p. 103). Ou, melhor dizendo, o fato de que o comportamento do sistema climático não corresponde às expectativas dos modelos significa que a natureza tem um defeito. Plimer (2009, p. 387) cita-nos um estudo publicado na revista Nature em 2002 sobre o resfriamento do continente antártico, no qual os autores embaraçosamente reconhecem que "o resfriamento continental da Antártida, principalmente a sazonalidade do resfriamento, apresenta desafios aos modelos de mudanças do clima e de ecossistemas". O mundo real contraria os resultados dos modelos, e isso é um problema gravíssimo!! Constrói-se um modelo e espera-se que o mundo real corresponda a ele, e se ele não corresponder é porque há algo de errado com o mundo!! A frustração de nosso ideal de ordem natural, a 


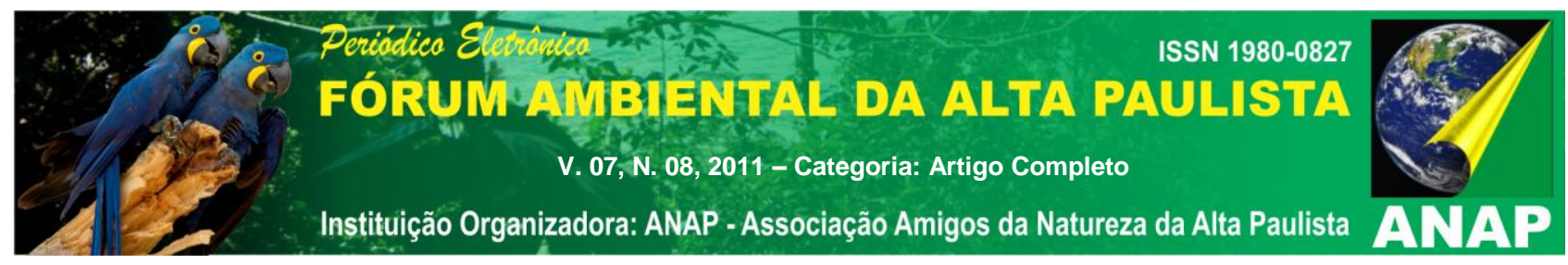

inadequação entre a teoria e o mundo, que sob qualquer outra circunstância implicaria no mínimo em uma revisão da teoria, é explicada pelo IPCC como uma deformidade no mundo, nunca na teoria, um gravíssimo erro epistemológico do qual poucos parecem ter se dado conta até agora. De fato, em ramos fracamente desenvolvidos da ciência, como a Climatologia, não só é possível estabelecer qualquer relação entre variáveis sem grande contestação, como por vezes torna-se inevitável o emprego de modelos e juízos a priori pois o menor esforço de elaboração teórica já representa um grande avanço nesse contexto - e seu uso inexplícito pode ser particularmente perigoso porque

\begin{abstract}
"uma curiosa transformação acontece a partir de um modelo a priori que não tem justificação empírica, através da repentina aceitação desse modelo como sendo a teoria (sem qualquer evidência empírica), até a culminante canonização do modelo como a quintessência da própria realidade" (Harvey, 1969, citado por Minshull, 1975, p. 126-127. Grifos no original).
\end{abstract}

Minshull alerta-nos para a gravidade desse raciocínio:

\begin{abstract}
"Ao ler a simples afirmação na página de que o modelo não deve ser confundido com a realidade, aqueles não familiarizados com modelos podem se perguntar como é possível que alguém nesse mundo incorra em semelhante erro. Infelizmente, a experiência nos mostra que esse erro é cometido muito freqüentemente, e aqueles com maior experiência no uso dos modelos e na pesquisa sobre sua natureza são os mais preocupados em dar esse alerta. Em casos extremos podemos nos deparar com situações ridículas nas quais, digamos, onde realidade e modelo não se encaixam, o modelo ser defendido e a porção particular da realidade ser ignorada ou rejeitada porque ela não se encaixa numa idéia induzida pelo modelo de como a realidade deveria ser" (Minshull, 1975, p.132-133).
\end{abstract}

Como se sabe, porém, a situação ridícula de rejeitar a realidade em defesa do modelo é justamente a postura adotada pelo IPCC. Mas seriam os modelos climáticos empregados pelo IPCC assim tão confiáveis a ponto de sua incompatibilidade com o mundo poder ser seguramente interpretada como um defeito no funcionamento do sistema climático e, o que é pior, de servirem de base para a elaboração das mais diversas políticas públicas para toda a humanidade ao longo do século XXI? Deixamos com o próprio IPCC a tarefa de responder a essa pergunta. Na Tabela 4.2.1 estão resumidos o conjunto de forçamentos inseridos em cada modelo empregado pelo IPCC para as projeções de mudanças climáticas durante o século XXI. As células verdes na tabela indicam que o forçamento foi incluído nas simulações; as amarelas indicam que 0 forçamento varia com o tempo em simulações do século XX, mas é mantido constante ou 


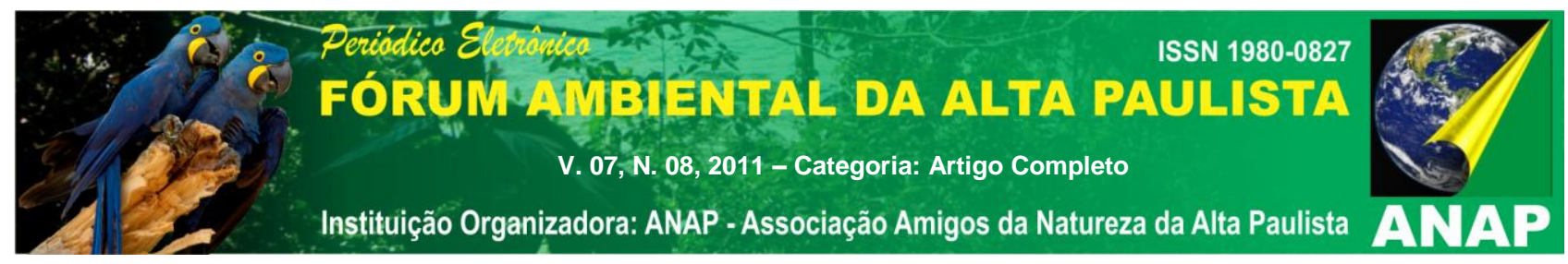

em distribuição anual cíclica para a integração dos cenários durante o século XXI; em violeta, o forçamento é representado em $\mathrm{CO}_{2}$-equivalente; em vermelho, o forçamento é incluído de acordo com os dados descritos em http://www.cnrm.meteo.fr/ensembles/public/results/results.html; em azul escuro, de acordo com Boucher and Pham (2002, citado por IPCC, 2007); em laranja, de acordo com Yukimoto et al (2006, citado por IPCC, 2007); em azul claro, de acordo com Meehl et al (2006b, citado por IPCC, 2007); em rosa, de acordo com http://aom.giss. nasa.gov/IN/GHGA1B.LP; em preto, de acordo com http://sres.ciesin.org/final_data.html; finalmente, os espaços em branco indicam que o forçamento não foi incluído, nem nas simulações do século XX, nem do XXI. O IPCC aponta os progressos no tratamento dos aerossóis nos modelos ocorrido desde o seu Terceiro Relatório (TAR); no entanto, a tabela doerá na vista de qualquer leitor minimamente inteligente, que poderá dizer se os sacrossantos modelos do IPCC são ou não são uma excelente e confiável ferramenta de descrição do sistema climático e de previsão de mudanças climáticas (ONÇA, 2011). 


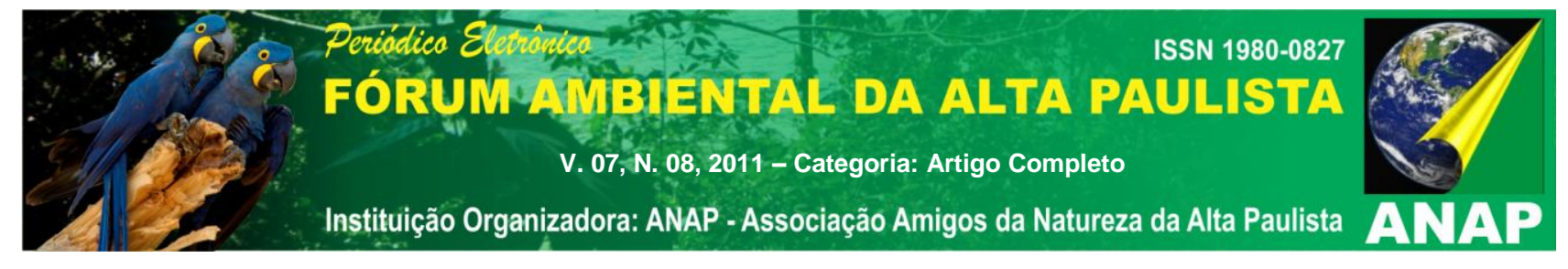

TABELA 4.2.1 - MODELOS UTILIZADOS PELO IPCC E SEUS FORÇAMENTOS (Fonte: ONÇA, 2011 adaptado de IPCC, 2007, p.756). 


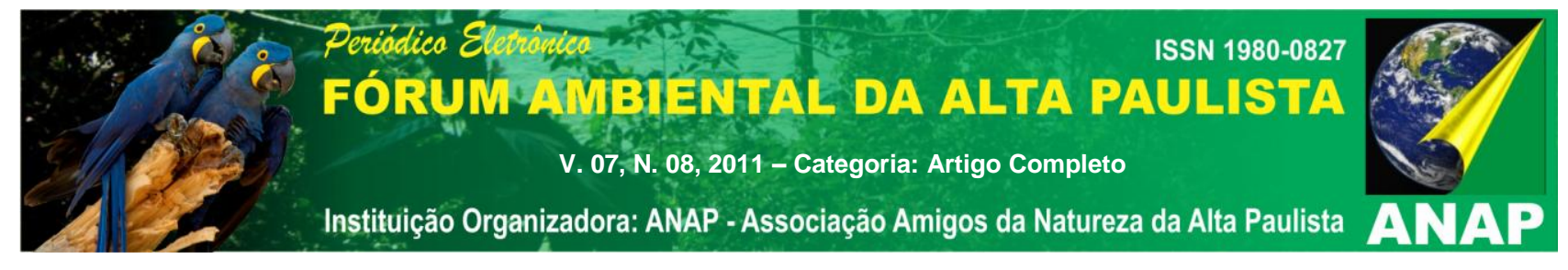

\begin{tabular}{|c|c|c|c|c|c|c|c|c|c|c|c|c|c|c|c|c|c|c|}
\hline \multirow{3}{*}{ Modelo } & \multicolumn{18}{|c|}{ Forçamentos } \\
\hline & \multicolumn{6}{|c|}{ Gases estufa } & \multicolumn{10}{|c|}{ Aerossóis } & \multicolumn{2}{|c|}{ Outros } \\
\hline & $\delta$ & $\overrightarrow{0}$ & $\stackrel{N}{N}_{\mathbf{Z}}^{0}$ & 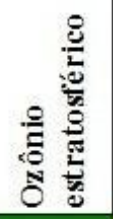 & 畩 & $\bigcup_{0}^{\infty}$ & $\vec{D}$ & $\begin{array}{l}\stackrel{8}{E} \\
\stackrel{\Xi}{2} \\
b\end{array}$ & 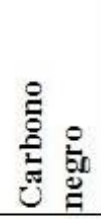 & 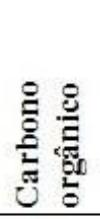 & 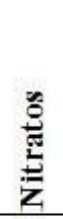 & 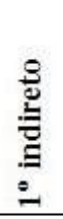 & 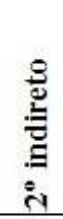 & $\frac{\pi}{\stackrel{5}{0}}$ & 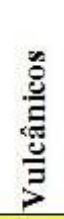 & 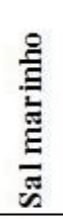 & 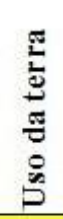 & $\frac{1}{0}$ \\
\hline \multicolumn{19}{|l|}{ BCC-CM1 } \\
\hline \multicolumn{19}{|l|}{ BCCR-BCM2.0 } \\
\hline \multicolumn{19}{|l|}{ CCSM3 } \\
\hline \multicolumn{19}{|l|}{ CGCM3.1(T47) } \\
\hline \multicolumn{19}{|l|}{\begin{tabular}{|l|} 
CGCM3.1(T63) \\
\end{tabular}} \\
\hline \multicolumn{19}{|l|}{ CNRM-CM3 } \\
\hline \multicolumn{19}{|l|}{ CSIRO-MK3.0 } \\
\hline \multicolumn{19}{|l|}{ ECHAM5/MPI-OM } \\
\hline \multicolumn{19}{|l|}{ ECHO-G } \\
\hline \multicolumn{19}{|l|}{ FGOALS-g1.0 } \\
\hline \multicolumn{19}{|l|}{ GFDL-CM2.0 } \\
\hline \multicolumn{19}{|l|}{ GFDL-CM2.1 } \\
\hline \multicolumn{19}{|l|}{ GISS-AOM } \\
\hline \multicolumn{19}{|l|}{ GISS-EH } \\
\hline \multicolumn{19}{|l|}{ GISS-ER } \\
\hline \multicolumn{19}{|l|}{ INM-CM3.0 } \\
\hline \multicolumn{19}{|l|}{ IPSL-CM4 } \\
\hline \multicolumn{19}{|l|}{ MIROC3.2(H) } \\
\hline \multicolumn{19}{|l|}{ MIROC3.2(M) } \\
\hline \multicolumn{19}{|l|}{ MRI-CGCM2.3.2 } \\
\hline \multicolumn{19}{|l|}{ PCM } \\
\hline \multicolumn{19}{|l|}{ UKMO-HadCM3 } \\
\hline UKMO-HadGEM1 & & & & & & & & & & & & & & & & & & \\
\hline
\end{tabular}




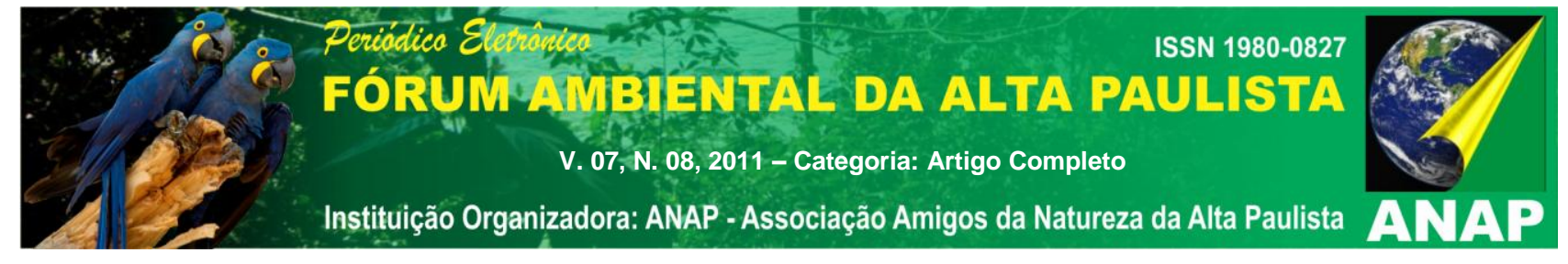





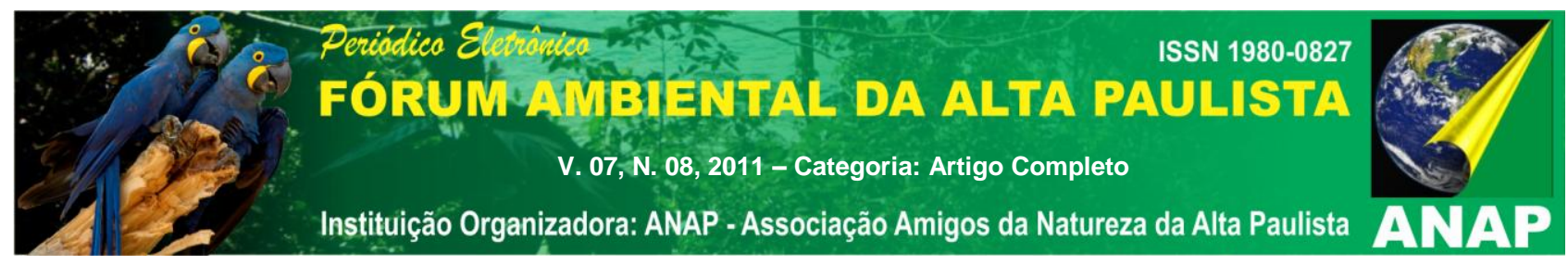

A tabela acima deixou bem claro que, para o IPCC, o funcionamento do sistema climático depende basicamente das concentrações atmosféricas de gases estufa. Toda a miríade de elementos que eles mesmo elencaram, como Sol, nuvens, oceanos, vulcões, florestas, uso do solo, entre muitos e muitos não considerados, neste momento, não possuem qualquer relevância para a confecção de um modelo confiável. Clima é gases estufa e ponto final. São estes pífios modelos que o IPCC considera dignos da mais elevada confiança, e é com base nos resultados desses mesmos pífios modelos que seus correligionários elaboram políticas públicas para toda a humanidade ao longo do século XXI. Modelos de computador não são entidades mágicas capazes de profetizar o futuro; são construções humanas e, como tal, são tão bons quanto o conhecimento humano neles inserido. Porém, como Lindzen (1992) vai enfatizar, "infelizmente existe uma tendência geral entre o público leigo de aceitar sem discussão qualquer informação gerada por um computador suficientemente potente".

\subsection{Exemplo de Um Modelo Aquecimentista Puntual}

Os modelos nada mais são que centenas e centenas de linhas de código de programação que visam expressar fenômenos ou simular os mesmos. Contudo, para funcionarem, como foi explanado, os processos precisam ser convertidos em equações matemáticas. Para os processos de integração, estas equações necessitam ser diferenciais envolvendo a variável tempo cronológico.

Esta parte do trabalho propôs a exemplificação de como se elabora um modelo muito simples em que a temperatura de um dado ponto será determinada somente pela forçante radiativa do $\mathrm{CO}_{2}$ que é de cerca de $1,66 \mathrm{~W} \cdot \mathrm{m}^{-2}$. A condição inicial das variáveis será a concentração atual normal da atmosfera do $\mathrm{CO}_{2}$, estabelecida em 330ppm, e uma aberração chamada Temperatura Média Global, que será da ordem de $15,0^{\circ} \mathrm{C}$. A integração será realizada em intervalos de 900 segundos, embora não fosse necessário tal procedimento, dadas as condições lineares do problema, escolheu-se utilizar este valor para manter a fidelidade ao uso nos outros modelos integradores. Assim, o tempo inicial será o ano de 2000 e o final, 2100. Como um ano tem 31.536.000s, 100 anos terão 3.153.600.000s, que em passos de 900s significará 3.504 .000 passos de "integração". 


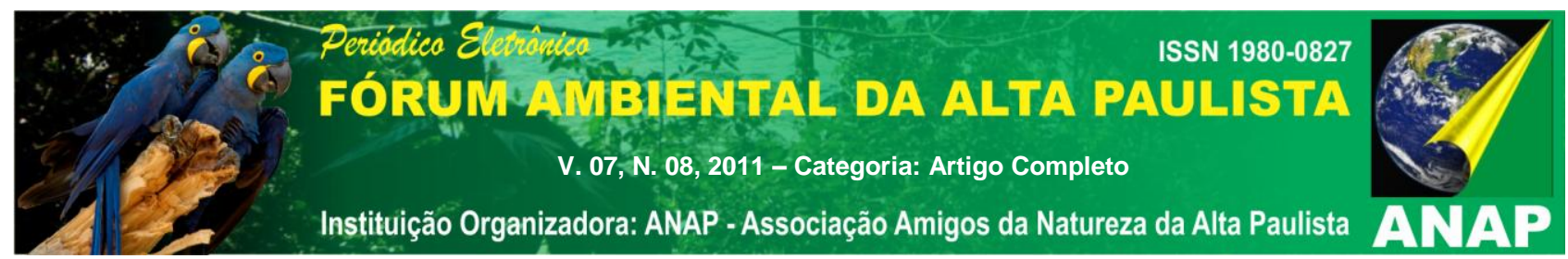

Para estabelecer uma relação linear, optou-se em utilizar uma taxa mais baixa de concentração de $\mathrm{CO}_{2}$ e uma temperatura inferior também, em uma Terra "antes do período industrial", como gostam de afirmar os ambientalistas. Assim sendo, o forçamento radiativo era menor e a Temperatura Média Global poderia ser na ordem de 12,7ํㅡ. Se o crescente lançamento de gases estufa chegar ao dobro, digamos 660ppm, teremos um forçamento radiativo muito intenso e que atingirá uma Temperatura Média Global extremamente alta de $30,0^{\circ} \mathrm{C}$. Um cenário cuja probabilidade de acontecer seria muito próxima de zero e, portanto, deveria ser descartado (embora muitos pseudocientistas adorariam utilizá-lo, correndo séria tentação). Desta forma, tal comportamento da forçante necessita ser "ajustado", obtendo então uma temperatura mais "branda", de cerca de $20,0^{\circ} \mathrm{C}$, ou seja, $5,0^{\circ} \mathrm{C}$ a mais que a "atual" Temperatura Média Global (Figs.4.3.1 e 4.3.2).

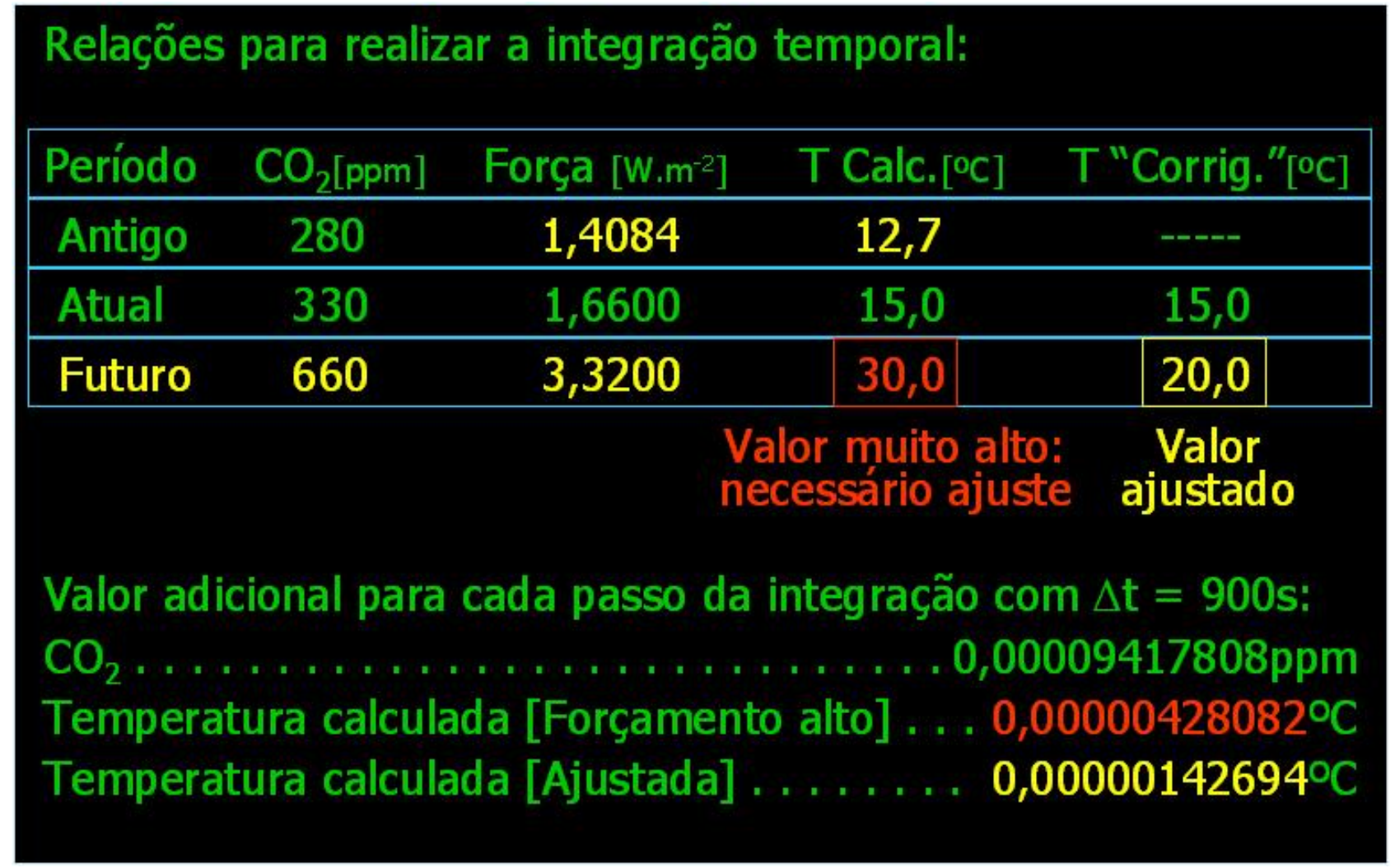

Fig.4.3.1: Forçamentos radiativos "impostos" para o modelo. Em 100 anos, com o dobro da concentração de $\mathrm{CO}_{2}$ atuais, o modelo extrapolou muito o valor da suposta Temperatura Média Global. Tal comportamento necessita ser ajustado, ou "atarrachado", como comentam os modeladores. Note que os valores dos incrementos de temperatura foram obtidos pela divisão do número de passos que o modelo necessitará integrar em 100 anos, para subir de $15,0^{\circ} \mathrm{C}$ para $30,0^{\circ} \mathrm{C}$, no cenário ultrapessimista, e de $15,0^{\circ} \mathrm{C}$ para $20^{\circ} \mathrm{C}$, no cenário pessimista (Fonte: Felicio, 2009). 


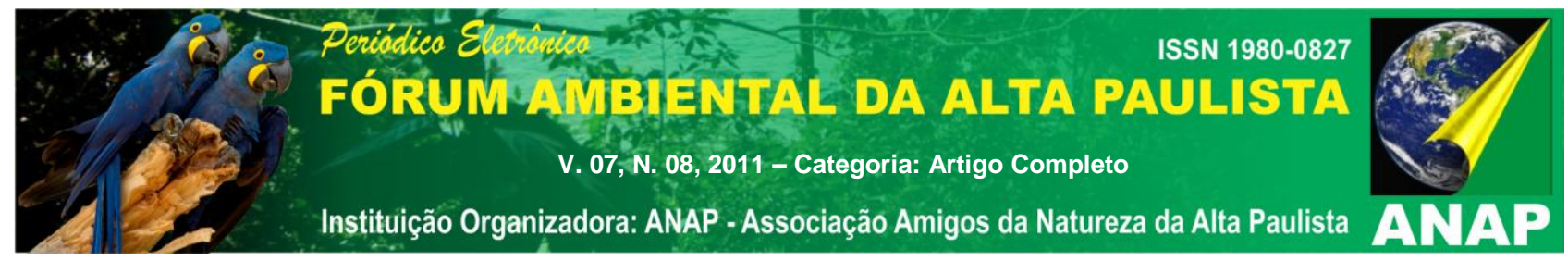

Uma vez que se estabeleceu a lógica do processo, bastará equacionar o problema e programar o computador com as linhas de código específicas para o fato. Neste caso, em apenas sete linhas será possível criar o elemento amplificador interno ao modelo que fará com que a temperatura suba, conforme sobem as concentrações de $\mathrm{CO}_{2}$, baseando-se "cientificamente" na sua forçante radiativa. Assim sendo, a cada passo da integração, a concentração subirá cerca de $9,41 \times 10^{-5} \mathrm{ppm}$. A relação da forçante radiativa e sua concentração (FRad) será obtida multiplicando-se a crescente concentração pelo valor de referência de $1,66 \mathrm{~W} \cdot \mathrm{m}^{-2}$ e este produto será dividido pela atual concentração. A variável Temperatura Média Global, obtida pela forçante mais intensa (TempCalcForca) será obtida pela sempre crescente forçante radiativa (FRad) que será multiplicada pela temperatura de referência de $15,0^{\circ} \mathrm{C}$ e dividindo este produto também pela referência da forçante radiativa de $1,66 \mathrm{~W} \cdot \mathrm{m}^{-2}$.

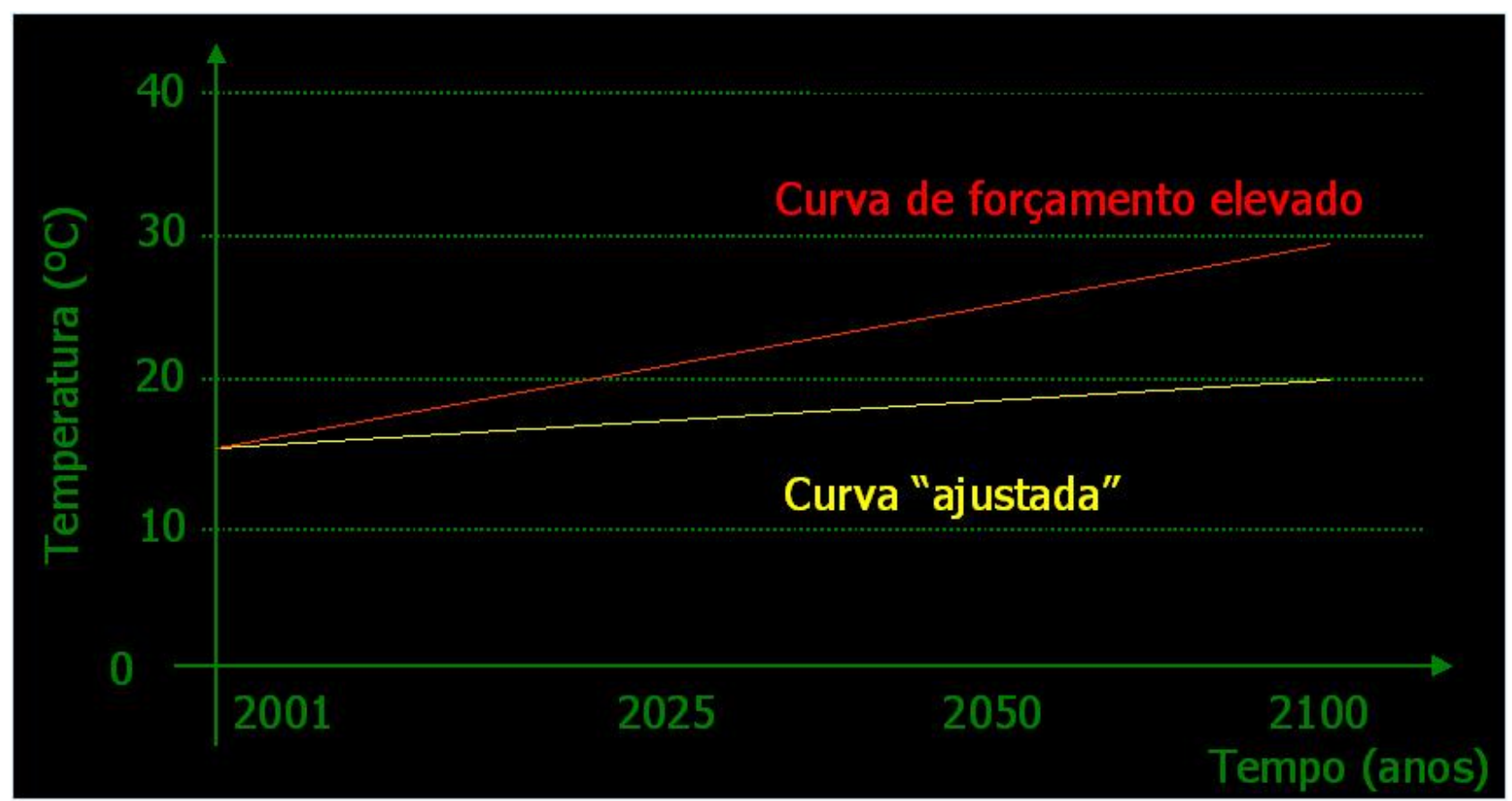

Fig.4.3.2: O comportamento do modelo exemplificado é linear, apenas para mostrar como dentro de um modelo mais elaborado, uma das variáveis pode estar simplesmente sendo utilizada para amplificar ondas internas. No exemplo deste trabalho, o forçamento mais elevado, linha vermelha, será descartado e ajustado para um mais brando, linha amarela (Fonte: Felicio, 2009).

Como visto, tal valor expressou-se muito alto e deve ser ajustado para algo mais palatável. Assim, no passo seguinte, a Temperatura Média Global será ajustada para apresentar o resultado de $15,0^{\circ} \mathrm{C}$, se a concentração de $\mathrm{CO}_{2}$ for a atual, mas, conforme 


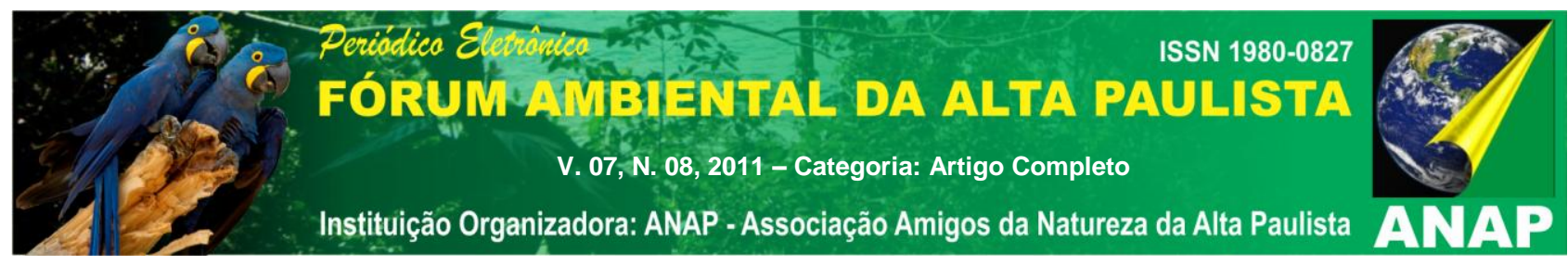

cresça, deverá ser um quinto do valor da forçante radiativa, a título de atenuar o seu incremento (TempCalcAjust). Desta forma, uma constante cujo valor é 0,332 foi obtida pela divisão dos $1,66 \mathrm{~W} \cdot \mathrm{m}^{-2}$ por cinco e obteve-se o "pulo do gato" dentro do modelo, através de uma regra de três simples, onde as atribuições foram estabelecidas, baseadas na realidade atual de concentração de gás, sua forçante radiativa e a "elevação segura", que conduzirá a um valor confortável de incremento da aberrante Temperatura Média Global (Fig.4.3.3).

E assim, no final, o pequeno algoritmo deste modelo, após calcular os seus 3.504.000 passos, exibirá o valor ajustado para a Temperatura Média Global que tanto se queria obter. Nestes termos, se o leitor do trabalho entendeu que o procedimento só serviu para justificar um resultado que já era esperado, acertou!

Faz-se a ressalva de que tal modelo não utilizou a variável tempo cronológico dentro do processo das equações, simplesmente porque não havia a necessidade de imediato. Esta variável temporal foi utilizada apenas para controlar as integrações. Os modelos reais possuem equações muito mais sofisticadas e que necessitam diversos controles específicos para que os resultados das mesmas não apresentem divergências significativas. Contudo, esse mesmo modelo simples poderá se tornar muito mais "elegante", quando aplicado em linhas de grade e utilizando outras condições de existência e condições iniciais. O fato que se chama a atenção é que para tudo que ocorra lá dentro, não passará de linhas de código de um algoritmo qualquer que simplesmente expressa uma vontade, não uma realidade. 

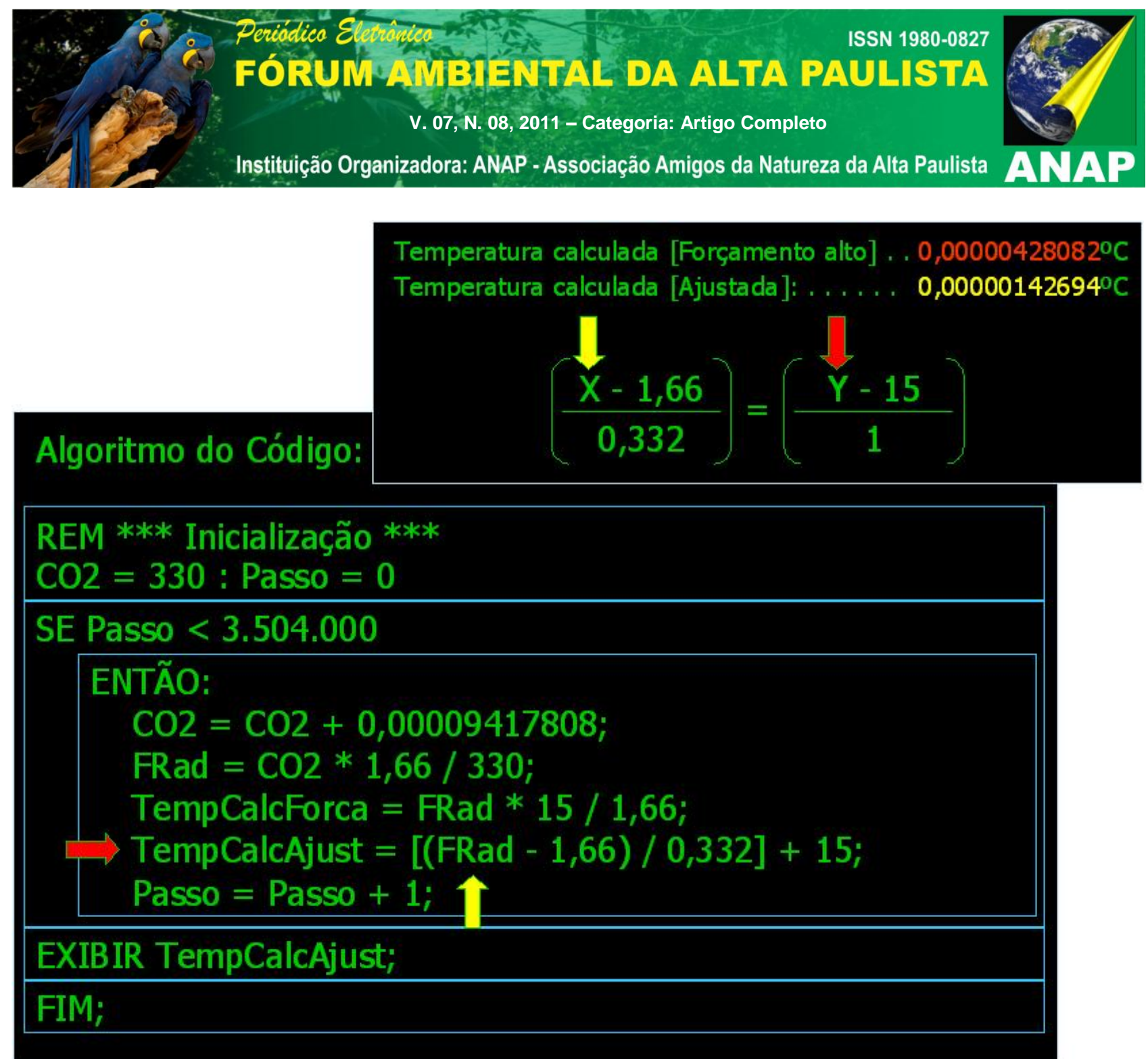

Fig.4.3.3: Aquecendo a Terra em sete linhas demonstrou que com apenas sete linhas de um algoritmo foi suficiente para elaborar um modelo aquecimentista que se baseia "cientificamente" no forçamento radiativo do $\mathrm{CO}_{2}$ e suas concentrações supostamente crescentes pela atividade humana. A seta amarela representa a forçante radiativa atrelada a uma visão de mundo. A seta vermelha expressa a atribuição, relacionando concentração do gás com a temperatura. Acima, a regra de três que estabelece o ajuste mais suavizado (Fonte: Felicio, 2009).

\section{CONCLUSÃO}

A Climatologia, bem como a Meteorologia, está se tornando simplesmente Ciência da Computação. O IPCC assume que "Ainda existe uma compreensão física incompleta sobre muitos componentes do sistema climático e seu papel nas mudanças climáticas. Incertezas centrais incluem aspectos dos papéis desempenhados pelas nuvens, pela criosfera, pelos oceanos, pelo uso da terra e pela combinação entre o clima e os ciclos biogeoquímicos" (IPCC, 2007, p. 21). Assim, extraindo-se todos esses elementos do 


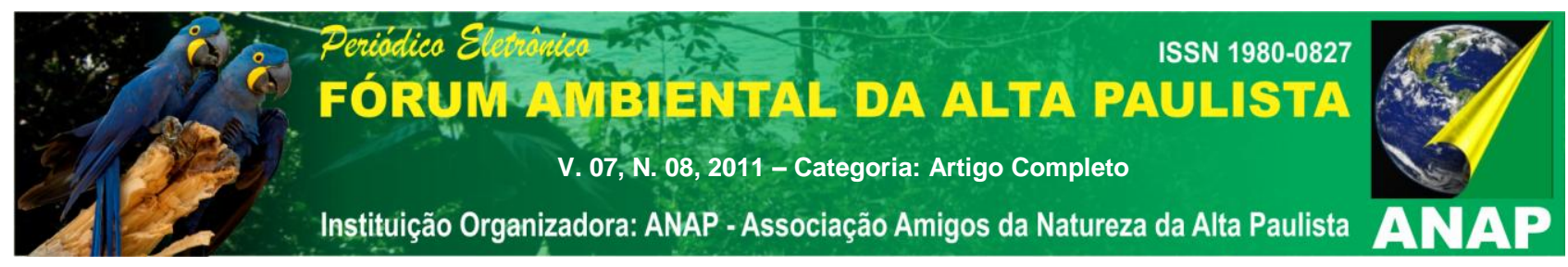

planeta e tendo em vista que esta é a confissão explícita do próprio IPCC, novamente faz-se uma pergunta crucial que não se quer calar:

Afinal, o que o pessoal do IPCC modela de clima?

A resposta, mais uma vez é perturbadora: NADA! Eles modelam as suas elucubrações mentais (ou débeis, para ser mais preciso) em que o fator antrópico - gases estufa - são o determinista do clima!

Então, como é impossível se realizar um experimento com a verdadeira Terra, a atribuição da mudança climática deve ser conduzida por meio de modelos - se o modelo disser que sim, então a mudança climática é de origem antrópica, e se o modelo disser que não, possibilidade altamente improvável dadas as circunstâncias, ela é de origem natural ou um artifício de erros de medições. Mas se, conforme vimos, os modelos estão muito longe de representar com a requerida fidelidade o sistema climático, representando muito mais a idéia que seus elaboradores fazem deste sistema - ou seja, eles não representam com segurança o mundo, mas a visão de mundo que os seus idealizadores querem - segue-se daí que a atribuição da mudança climática está indissociavelmente condicionada à visão de mundo desses indivíduos. Em última instância, segundo esse raciocínio de que a resposta está nos modelos (e somente nestes modelos), conclui-se que a ÚNICA PROVA de que a mudança climática É de origem antrópica FOI PORQUE ALGUNS CIENTISTAS DISSERAM que ela É antrópica. Esse é o pavoroso coquetel de circularidade, petição de princípio e apelo à autoridade que constitui o sólido embasamento para as políticas determinantes de nossas vidas durante este século.

Não importa como é o modelo nem quais são suas características; o bom cientista deve sempre ter em mente que o modelo é uma simplificação da realidade. Não há nada de errado em utilizarem-se essas simplificações com finalidades didáticas em cursos de Meteorologia ou Climatologia, nem mesmo em isolar apenas um ou alguns componentes de um modelo para iniciar o estudo de seu papel no sistema climático, desde que se deixe claro que ele se trata de uma simplificação. Quando, porém, a simplificação é extrema, quando os modelos incluem entre seus forçamentos climáticos apenas os gases estufa, não podemos mais chamá-lo de simplificação, e sim de DISTORÇÃO, especialmente 


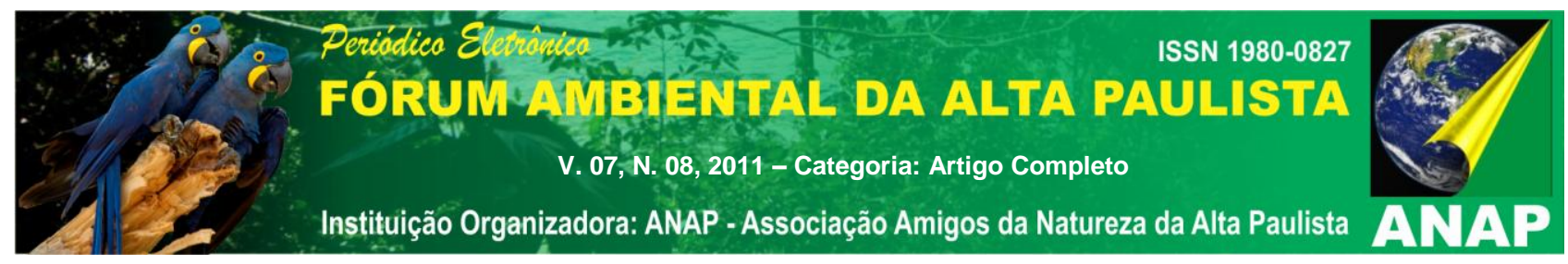

quando os forçamentos selecionados correspondem muito mais às preferências pessoais dos aquecimentistas do que a elementos mais importantes na composição do sistema climático (MINSHULL, 1975, p. 121-122). Já quando esses instrumentos didáticos distorcidos deixam os laboratórios da academia para ganharem o mundo como determinantes dos destinos da humanidade, a isto denominamos irresponsabilidade ou crime.

Assim, usando esses modelos reducionistas, eles conseguem preparar a legitimação da ação de governos por todo o planeta, principalmente aqui no Brasil, onde os processos para a mitigação de formas de transformação de energia, de venda de produtos "verdes e sustentáveis", de aplicação de novos impostos e o fortalecimento de grandes monopólios vão de vento em popa. Evoca-se sempre a idéia do planeta-máquina, escondendo a verdade de que isto é apenas uma metáfora que mal serve para realizar uma compreensão de mundo. Os modeladores atmosféricos que atuam no IPCC nem sequer tentam exprimir todos os processos que tais "máquinas" da Natureza operam, ignorando-os com omissões tenebrosas. Primeiramente tais omissões ocorrem pela pura e simples ignorância dos indivíduos frente aos fatos, mas a seguir, a omissão torna-se criminosa, pois atrela todo o desenrolar da dinâmica climática à atividade de produção humana, com seus desdobramentos sobre as sociedades. Deve-se entender que esta atividade é expressa em toneladas de dióxido de carbono que são liberadas para a atmosfera, mas não todos os outros problemas ambientais reais que possam surgir. Assim sendo, mascaram-se os verdadeiros vilões, mas resolve-se o problema do "aquecimento global" através dos falaciosos esquemas de créditos de carbono.

E assim, ONGs, pseudocientistas e políticos engajados na causa vêm implementando, na calada da noite, toda a mudança na sociedade, principalmente na brasileira, onde ainda cerca de $31,1 \%$ da população está no nível de pobreza extrema e mais de $20 \%$ ainda passa fome grave (IBGE, 2010). Todas as mudanças são realizadas baseando-se nos cenários projetados por modelos matemáticos de clima que são completamente falaciosos. As leis são alteradas com a "ajuda" dos parlamentares "comprometidos com a causa de salvar a natureza". São implementadas pelos poderes executivos de diversas esferas, também "comprometidos em salvar o planeta" e restará ao judiciário fazer cumprir as normas, como sempre, cegamente. As implementações 


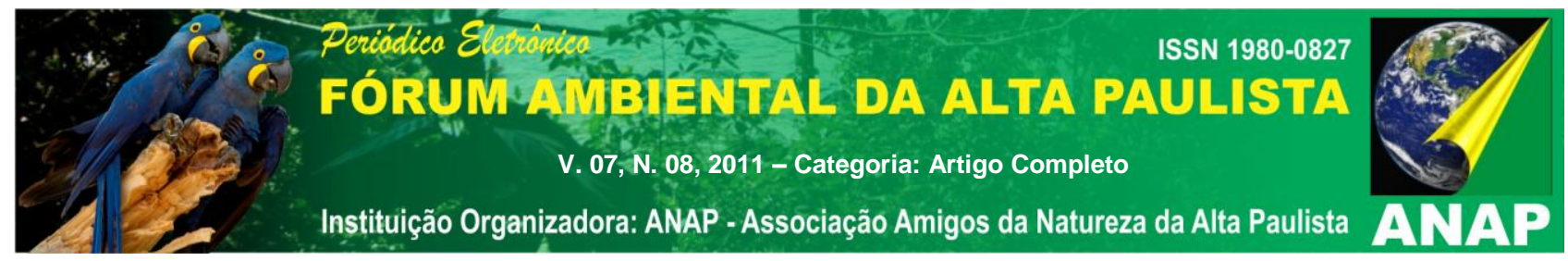

tornam-se legais, mas nunca deixarão de ser imorais. Até quando haverá a passividade? Este é o chamado processo democrático que realmente de democrático não tem nada. As decisões são tomadas respeitando os desejos das ONGs, ou seja, dos interesses internacionais, pois estas são financiadas por tais governos. A relação é aberta e clara. Para quem ainda tem dúvidas, basta verificar o inventário de carbono realizado para o Estado de São Paulo, onde Bruno Covas, com apoio da embaixada britânica no Brasil, relata que "pela primeira vez verificamos que são os AUTOMÓVEIS da frota paulista que geram a POLUIÇÃO do $\mathrm{CO}_{2}$ no estado, superando a emitida dela indústria" (FOLHA DE SÃO PAULO, 2011). A falsidade na sentença é ampla. Primeiro porque o dióxido de carbono não é um poluente. Se assim o fosse, estaríamos mortos na primeira respirada, pois as taxas são superiores a 50.000ppm. Ele é o gás da vida e serve a tudo que é orgânico no universo biológico conhecido. A seguir, consegue atrelar a culpa desta "poluição" para os automóveis, portanto, um bem do cidadão, que mais uma vez receberá a culpa, ou a incumbência de ter que pagar a conta, sempre interminável, do meio ambiente. Ao mesmo tempo, desvia do foco as verdadeiras poluidoras, na escala local, que seriam as indústrias que não trabalham seus dejetos e afluentes. Esta é a verdade, mas sempre mascarada com compromisso ambiental. $\mathrm{O}$ carro do cidadão não pode, mas o esgoto que corta a cidade de São Paulo ao meio, pode!

O trabalho demonstrou que as mudanças impostas às sociedades são baseadas em saídas de modelos matemáticos trabalhados em computador que nada tem de realísticos. São códigos de programação escritos para exibirem as respostas que os aquecimentistas desejam: que $\circ \mathrm{CO}_{2}$ controla o clima da Terra! Não há nada mais determinista que tal pensamento reducionista destes pseudocientistas. Um exemplo simples foi apresentado para mostrar como são elaborados tais "ajustes" dentro destes modelos. Portanto, os modelos matemáticos em computador estão muito longe de expressar o mais simples dos processos da natureza climática e suas derivações. Que dizer então de toda a complexidade intrínseca à dinâmica climática? Ao mesmo tempo, os modelos integradores apresentam alta divergência quando submetidos a intervalos de tempo de apenas sete dias. Pode-se imaginar o que significa então um cenário projetado para daqui há 100 anos? Simplesmente nada de real sai destes modelos. 


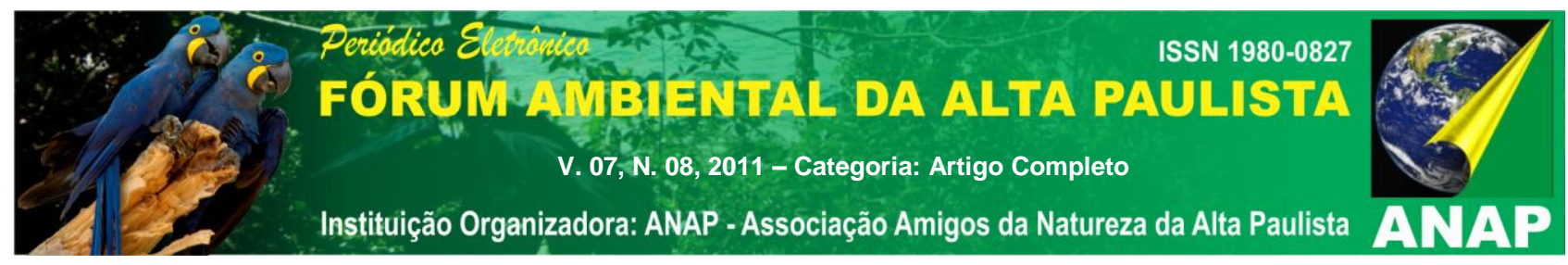

Os fatos estão cada vez mais escancarados e só não vê quem realmente não o quer, pois a diferença entre a verdade e a ficção científica é que esta última precisa fazer sentido. A verdade agora é que não há mais diferenças entre os filmes hollywoodianos e a "ciência climática e suas derivações de interdisciplinaridade". Todas fazem parte do encantado mundo da Fantasia.

\section{HOMENAGEM}

O artigo é dedicado à memória de Rui Golçalo Moura, falecido aos 80 anos em um domingo, 27 de junho de 2010. Ele foi engenheiro e homem de ciência brilhantes, com uma paixão pela verdade científica. Graduou-se como melhor aluno do seu curso, no Instituto Superior Técnico (IST), em 1957. Trabalhou durante 30 anos como engenheiro eletrotécnico. Foi simultaneamente assistente e professor convidado da cadeira de Eletrotecnia Teórica, Medidas Elétricas e Alta Tensão do IST entre 1970 e 1976. Serviu na Comissão Européia de 1987 a 1990 e na Comissão Técnica e Científica do Plano Energético Nacional de 1989 a 1992. Depois da sua aposentadoria, em 1992, dedicou-se ao estudo do clima, de forma a poder contribuir para um debate que considerava fundamental. Diferentemente de outros eletrotécnicos daqui do Brasil que se aventuraram pela área da Meteorologia e Climatologia sem nenhum conhecimento de causa, Rui possuía uma mente verdadeiramente brilhante, tornando-se mais que um especialista em dinâmica do clima; também aprendeu a se comunicar efetivamente na era moderna, e criou seu sítio de internet, em 2005. Conjuntamente com Jorge Pacheco Oliveira, traduziu o livro "A Ficção Científica de Al Gore", de Marlo Lewis Jr., publicado pela Booknomics, 2008. As equipes de pesquisa Climageo e FakeClimate prestam esta homenagem a este grande debatedor português das falácias do "aquecimento global" e as políticas públicas atreladas a esta que já é considerada a maior impostura científica de todos os tempos (MOURA, 2011; FAKECLIMATE, 2011).

\section{REFERÊNCIAS}

BLÜCHEL, K.G. A fraude do efeito-estufa - aquecimento global, mudança climática: os fatos. São Paulo, PHL editora, 2008. 


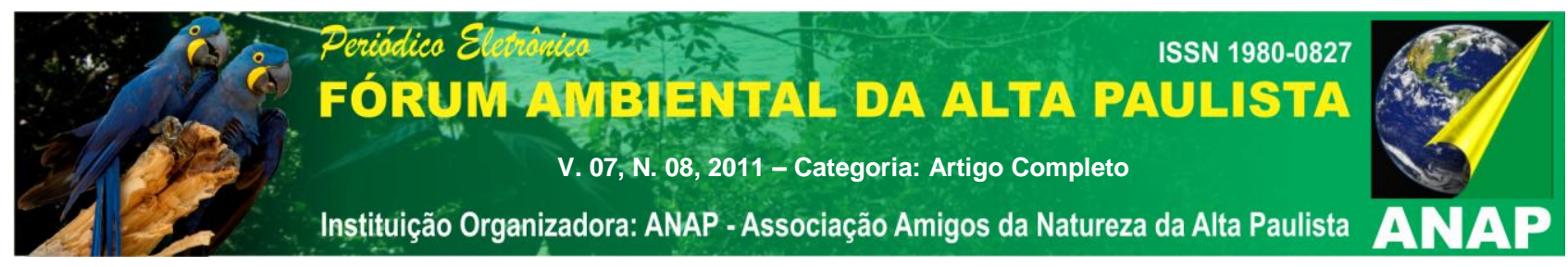

FAKE CLIMATE. Artigos publicados diversos.

Disponível em: <http://fakeclimate.com>. Acesso em: 10 maio 2011.

FELICIO, R. A. Modelos e parametrizações - escalas de observação e teoria dos erros. In: Aula 11 do curso de graduação em Geografia: Mudanças Climáticas Globais e Implicações Atuais. Faculdade de Filosofia, Letras e Ciências Humanas, São Paulo: USP, 2009.

FOLHA DE SÃO PAULO. Inventário do Carbono no Estado de São Paulo. Edição de 04 maio de 2011. p. A2.

IBGE, 2010. Resultado do Censo 2010.

Disponível em:

<http://www.ibge.gov.br/home/estatistica/populacao/censo2010/default_sinopse.shtm>.

Acesso em: 11 maio 2011.

HUME, E. The day after. Produção Cinematográfica para televisão. MGM, 1983.

IPCC. Climate change 2007: the physical science basis. Cambridge, New York; Cambridge University Press, 2007, 996 p.

LINDZEN, R. S. Global warming: the origin and nature of the alleged scientific consensus. In: Regulation, p. 87-98, Spring 1992.

LINO, G. L. A fraude do aquecimento global. 2ª edição. Rio de Janeiro: Capax Dei, 2010, 146 p.

MARUYAMA, S. (tradução de SUGUIO, K.) Aquecimento global? 1a edição. São Paulo: Oficina de Textos, 2009, $125 \mathrm{p}$.

MINSHULL, R. An introduction to models in Geography. Essex, Longman, 1975.

MOLION, L. C. B. Efeitos de vulcões no clima. In: Cadernos de Geociências no 12. Rio de Janeiro, out/dez 1994, p. 13-23.

MOURA, R. G. Mitos climáticos. 2011.

Disponível em: <http://mitos-climáticos.blogspot.com>. Acesso em: 10 maio 2011.

ONÇA, D. S. "Quando o sol brilha, eles fogem para a sombra...": a ideologia do aquecimento global. Tese de doutorado, Faculdade de Filosofia, Letras e Ciências Humanas da Universidade de São Paulo, 2011.

PLIMER, I. Heaven and Earth. Maryland, Taylor Trade Publishing, 2009.

UNITED STATES SENATE. U. S. senate minority report: more than 1000 international scientists dissent over man-made global warming claims scientists continue to debunk "consensus" in 2010, U.S. Senate Environment and Public Works Committee Minority Staff Report, 2010. 